\title{
Chasing trends at the micro-level: The effect of technical trading on order book dynamics
}

\author{
Carl Chiarella ${ }^{\mathrm{a}}$ and Daniel Ladley*b \\ ${ }^{a}$ UTS Business School, University of Technology Sydney, NSW 2007, \\ Australia \\ ${ }^{\mathrm{b}}$ Department of Economics, University of Leicester, LE17RH, UK
}

September 1, 2015

\begin{abstract}
Technical traders attempt to exploit trends in market prices and the order flow. Despite this little is known about how these traders behave in a micro-structure context. We consider a model of an order book based financial market. The market contains two groups: informed traders and technical traders. A numerical technique is used to identify a Markov perfect equilibrium of the trading game and so determine the optimal strategies. We find that technical trading rules are profitable and allow traders to increase their returns. The effect of technical traders on the market, however, is ambiguous. They decrease volatility and pricing errors but also increase trading costs despite primarily acting as liquidity suppliers.
\end{abstract}

Keywords: Market Micro-Structure, Technical Trading, Order Book, Market Efficiency, Dynamic Equilibrium

JEL codes: G10 C63

*Corresponding Author, E-mail: d.ladley@le.ac.uk, Telephone: +44 1162525285 


\section{Introduction}

The strategies and profitability of technical traders have received much attention in the finance literature, however, relatively little is known about the behavior of these traders in a micro-structure context. The rise of high frequency trading has made understanding this area increasingly important. Key to the strategies of many of these traders is the identification of trends or momentum in the market. Early identification allows traders to beat other market participants to the best prices and to make profits. Whilst for longer term investment the micro-structure costs and implications of trading may be ignored, for high frequency firms these are significant. Traders in these firms often turn over positions within a few seconds meaning that micro-structure considerations such as liquidity and price impact are vital.

In this paper we present a model of the interaction of informed and technical traders in a dynamics order book market. Informed traders know the fundamental value of the asset whilst technical traders trade based on trends in the order flow. The order submission strategies of both groups of traders are conditioned on the state of the market, the configuration of the order book, and, in the case of technical traders, the technical rules. We use a numerical approach in order to identify a Markov perfect equilibrium in which both types of traders behave optimally. The dynamics of the model are analyzed in order to understand how the presence of technical traders impacts the micro-structure dynamics and market quality including liquidity, stability and efficiency. The behavior of both groups of traders are examined and their strategies characterized.

Technical traders use information about past trades in order to predict future price movements. To do this they use a variety of approaches including data analysis, e.g. moving averages, break out rules etc, and visualization techniques, such as candle charts or Fibonacci arcs. Perhaps the most common are momentum based rules which attempt to identify trends in market price movements. Once these trends are identified traders may take positions to benefit from further price movements in the predicted direction. The economic evidence supporting the effectiveness of technical rules is mixed, for instance Marshall et al. (2006) find that candle stick strategies do not outperform the Dow Jones 
whilst Allen and Karjalainen (1999) are unable to find technical rules able to make excess returns on the S\&P500 index. In contrast Neely and Weller (2013) find that technical rules may give positive returns in FX markets and that rules which do this may be found computationally (Neely et al., 1997). Brock et al. (1992) test two key momentum based technical trading strategies finding that they make positive returns on the Dow Jones. Taylor (2014), however, finds that these positive returns may be restricted to certain historical periods. Despite the mixed evidence, these rules are employed by significant numbers of traders within financial markets, particularly at high frequencies. For instance Allen and Taylor (1990) and Taylor and Allen (1992) find that 90\% of traders used technical analysis and that this was particularly common at short horizons.

Recent empirical work has suggested that technical trading profits are moving from longer time periods to intra-day or possibly even shorter timescales (Schulmeister, 2009). This has coincided with a marked increase in the speed of trading. Prior to the late 1980's the majority of equity trade was conducted through market makers who set a bid price and offer price against which individuals could transact. With the rise of electronic market places this began to change. Computer technology meant that the order book could be maintained and trades matched electronically. Importantly this information could be fed to traders continuously. At the same time changes in regulation meant that individual traders could supply liquidity and compete with market makers. These shifts in market architecture have led to the rise of day trading and more recently algorithmic trading. ${ }^{1}$ A key strategy for both of these groups of traders is to attempt to make profits by predicting and riding short term trends in the market. Brogaard et al. (2014) notes that these traders are able to predict prices changes several seconds in advance.

Despite the rise in high frequency trading and the shortening of timescales over which technical traders may make profits there is little work considering the effect of technical traders in a micro-structure context. Closest to the work presented in this paper is that of Chiarella and Iori (2002) and Chiarella et al. (2009) who examine the role of chartists and fundamentalists in order book markets. Possibly the greatest challenge in these

\footnotetext{
${ }^{1}$ As of 2010 approximately $70 \%$ of American and 30-40\% of European equity volume was conducted by these firms (Haldane, 2010).
} 
studies comes from the specification of trader's order submission strategies. Even without the necessity of analytical tractability, finding optimal or even reasonable behaviors is difficult. As a result the information sets or strategies are often radically simplified or the order submission rules chosen based on rules of thumb. Here we employ a numerical technique that allows us to identify optimal strategies in a more general setting for traders who value assets using technical rules. This numerical approach was originally employed by Goettler et al. (2005) in their extension of the analytical model of Parlour (1998) to include a realistic micro-structure. This change, however, made the model analytically intractable, necessitating a numerical approach in order to identify a Markov perfect equilibrium and to analyze the behavior of the market. The requirements for this are very strict, in particular, in order that all payoff relevant information was contained in the state it was only possible to model a single type of trader who had a fixed distribution of valuations and could not modify orders after they were submitted. In later work Goettler et al. (2009) furthered this analysis for the case of asymmetric information with the possibility of traders canceling and resubmitting orders over time. Bernales (2014) used the same technique to look at the effect of trading speed on the profitability of high frequency traders and market quality. As a result of these changes traders types were not identical and the models no longer met the Markov perfect equilibrium requirement - the recent history of order submissions contained information not present in the order book. It was not possible to include this information in the state and still have a model which could feasibly be analyzed numerically. As a result whilst the converged state was not strictly a Markov perfect equilibrium, the result of the optimization was instead a stable set of strategies which were optimal given the available information. ${ }^{2}$

In this paper we build on the approach above to model the interaction of technical and informed traders in a dynamic order book based financial market. We focus on technical

\footnotetext{
${ }^{2}$ There are, additionally several papers which consider boundedly rational traders within these markets. For instance Ladley and Schenk-Hoppé (2009) use a model with zero intelligence traders to show that statistical features of order flow are in many cases a result of market micro-structure and not necessarily strategic behavior. Pellizzari (2011) uses an evolutionary approach to find optimal linear trading strategies for continuous double auctions. Lensberg et al. (2012) evolve ecology's of portfolio management and order submission strategies using genetic programming in order to quantify the effects of short selling bans and transaction taxes in order book markets.
} 
traders who use momentum based rules. This category of rules are widely used in real markets and have, in some circumstances, been shown to be profitable. By using the numerical approach of Pakes and McGuire (2001) and Goettler et al. (2009) we are able to derive optimal strategies such that conditional on the state of the market both groups of traders submit and modify their orders in such a way as to which maximize their expected payoff. Analysis of this model shows that traders using technical information make greater profits than those who do not. These profits are increasing as trader's information about the fundamental value becomes less precise. The presence of technical traders has an ambiguous effect on the market quality. The spread decreases but at the same time the number of orders in the book falls. The effective spread for informed traders increases indicating higher transaction costs. Price efficiency increases - the market price tracks the fundamental more accurately and volatility goes down. Analysis of the strategies of technical traders shows that they predominantly act as liquidity suppliers - using limit order more frequently, and market orders less frequently, than informed traders with the same valuations when technical traders are not present. These results contrast with the findings of Hendershott et al. (2011) high frequency traders, many of whom use momentum based strategies, increase liquidity within markets. Whilst technical traders within our model do supply liquidity their overall effect is ambiguous.

We find that the presence of technical traders results in the structure of the order flow better matching certain empirical observations. This suggests that these traders are vital in accurately capturing the behavior of markets at a micro-structure level. If technical traders do not have access to up-to-date fundamental information their profits are less than informed speculators who make money from their mispricings. Whilst technical information may be beneficial to the traders using it and the market as a whole it is not sufficient to protect these traders from exploitation by better informed individuals at short time intervals.

The paper proceeds as follows. Section 2 sets out the details of our model whilst Section 3 first describes aggregate market dynamics under the converged strategies before analyzing the trading behaviors. Section 4 concludes. 


\section{Model}

We consider a continuous time model of the trade of a single financial asset through an order book based market. The order book is defined as a discrete set of prices $\Pi=$ $\left\{p^{i}\right\}_{i=-\infty}^{\infty}$ where the distance between adjacent prices is constant and is referred to as the tick size $\delta_{P}$. At each price there is a queue of unfilled orders, $l_{t}^{i}$. These orders are sorted by submission time from earliest to latest. We adopt the convention that positive values in $l_{t}^{i}$ refer to buy orders and negative values to sell orders. Together these define the order book $L=\left\{l_{t}^{i}\right\}_{i=-\infty}^{\infty}$. The best bid is then given as $B(L)=\max \left\{i \mid l^{i}>0\right\}$ and the best ask as $A(L)=\min \left\{i \mid l_{i}<0\right\}$. If either set are empty the best bid and ask are defined as $B(L)=-\infty$ and $A(L)=\infty$. The order book operates under price and time priority. The order at the front of the highest (lowest) priced non empty queue - the best bid (offer) has priority. If an order is submitted and there exists a matching order in the book, the submitted order is treated as a market order and a trade occurs resulting in the existing order being removed. If no matching order exists the new order is entered into the book as a limit order at the submitted price for the specified quantity.

The asset has a fundamental value $v_{t}$ which evolves through time according to a stochastic process. The time between innovations in the fundamental value are exponentially distributed with mean $\lambda_{v}$. When an innovation occurs the fundamental value increases or decreases by one tick with equal probability. The set of prices is such that $v_{0} \in \Pi$ and therefore $\forall t, v_{t} \in \Pi$.

Traders may have imperfect information about the fundamental value. We model this by assuming that traders observe the fundamental value with a lag. Whilst the fundamental value at time $t$ is $v_{t}$ a trader with an information lag of $\tau$ observes $v_{t-\tau}$ when they come to the market. If traders have different lags the model is one of asymmetric information as in Goettler et al. (2009).

The market is populated by two groups of traders: Informed traders who trade based on their information on the fundamental value of the asset and Technical traders who trade based on short term trends in the order book dynamics. The type of a trader, $Z=\{I, C\}$, is determined when they arrive at the market and remains fixed for the 
traders' lifetime. A trader is of type informed, $Z=I$, with probability $\gamma$ and of type technical, $Z=C$, with probability $1-\gamma$. Each trader has an individual private valuation. This value is determined when they first enter the market, prior to taking any actions and does not change throughout the traders life time. The manner in which this valuation is determined is dependent on the type of the trader.

Informed traders have knowledge of the fundamental value of the asset. Their private valuation reflects this along with their exogenous motives for trade such as requirements from clients, hedging or liquidity needs. An informed trader's valuation is given by:

$$
V_{I}=v_{t-\tau_{I}}+\nu
$$

in which $\nu$ is their exogenous motive for trade and $\tau_{I}$ is the informed traders lag in observing the fundamental value.

Technical traders believe that future asset price changes may be predicted based on historical trends. There are many technical rules which may be investigated in this context, however, we restrict the analysis to consider one example from the relatively widely used class of momentum based rules. We model technical traders as being speculators and therefore having no intrinsic motive for trading beyond buying the asset for less than the fundamental value or selling it for greater. A technical traders valuation, $V_{c}$ is, therefore, given by their current estimate of the fundamental value. This is comprised of their information about the fundamental, observed with lag $\tau_{C}$ and their estimate of the change in the fundamental value coming from their technical rule:

$$
V_{C}=v_{t-\tau_{C}}+\delta_{t}\left(m_{t}\right)
$$

where $\delta_{t}\left(m_{t}\right)$ is a price adjustment based on the value of the traders technical rule. Traders base their adjustment on trends in the market price, $m_{t}$, which are calculated as:

$$
m_{t}=\lambda m_{t-1}+(1-\lambda) q_{t}(A(L)-B(L))
$$

where $q_{t}$ is the quantity of the market order involved in the trade at time $t$ and 
$A(L)-B(L)$ is the spread. $m_{t}$ is updated every time a trade occurs. In the event of an increase in the relative number of buy market orders to sell market orders this measure will be positive as the trade price, the best ask, will be above the mid price. As such the trend will be positive and the technical trader will have a valuation which corresponds to an increase in price. Similarly an increased number of sell market orders will lead to a negative trend and an estimate of the fundamental below the current observed value.

If $\tau_{C}=\tau_{I}$ the two groups of traders are equally well informed. In contrast if $\tau_{C}>\tau_{I}$ informed traders have better information about the fundamental value than technical traders and vice versa for $\tau_{C}<\tau_{I}$.

The times between new trader arrivals are exponentially distributed with parameter $\lambda_{a}$. On arrival a trader may trade a single unit of the asset - the choice whether to buy or sell is endogenous. Traders may choose to submit an order - either to buy or sell one unit of the asset at any price in the order book or to wait.

After submitting an order which has not executed a trader re-enters the market after a random amount of time. The lag in re-entry is drawn from an exponential distribution with parameter $\lambda_{r}$. As such traders may not instantly revise orders in response to changes in the state of the market and are exposed to picking off risk associated with the changing order book and fundamental price. When a trader re-enters the market they may cancel their existing order and submit a new orders or they may leave their existing order in place. Leaving the existing order in place has the advantage that the time priority, i.e. the orders' place in the queue, is preserved. A trader may potentially re-enter the market multiple times revising their orders on some or all occasions, however, once a traders' order has executed they permanently leave the market and do not return.

\subsection{Trader Maximization Problem}

Traders are risk neutral and gain utility from trade based on their private valuation. The payoffs from trade are discounted back to the time of entry at the rate $\rho$. This rate represents costs associated with delaying transactions and possible lost opportunities in connected trades rather than the traditional opportunity cost of capital associated 
with investment. On the timescales that micro structure models typically operate the opportunity cost of capital is negligible, however, the costs associated with missed trading opportunities may be substantial.

When a trader enters, or re-enters, the market they are faced with the problem of submitting an order which maximizes their expected payoff conditional on the current state of the world. The set of possible actions open to a trader in state $s$ is $X(s)$ where an action is a price quantity pair $a=(p, q)$ such that $p \in \Pi$ and $q \in-1,0,1$ where -1 is an order to sell one unit, 1 an order to buy one unit and 0 corresponds to the trader waiting and not submitting an order ${ }^{3}$. This set contains all possible price-quantity pairs corresponding to new orders along with the option for the trader to keep their existing order in the book (if it exists).

Traders base their choice of action on the state of the world. The state at time $t$ consists of all orders in the order book $(L)$, the traders type $(Z)$, the traders private valuation $\left(V_{Z}\right)$ which itself is contingent on the type of trader, and the details of the traders' previous order if one exists $(p, q, \tilde{n})$ where $\tilde{n}$ is the orders place in the queue at price $p$. Both traders know the fundamental value with a lag $\left(v_{t-\tau_{I}}\right.$ or $\left.v_{t-\tau_{C}}\right)$ whilst technical traders additionally know the trend $\left(m_{t}\right)$.

When an informed trader enters the market their expected payoff for action $\tilde{a}$ in state $s$ is:

$$
\pi_{I}\left(s, \tilde{a}, t_{r}\right)=\int_{0}^{t_{r}} \int_{-\infty}^{\infty}\left(e^{-\rho t} \tilde{q}\left(\nu+v_{t}-\tilde{p}\right) \Phi(\tilde{a} \mid s, t, \nu)\right) f(v \mid s, t) d v d t
$$

For ease of notation we normalize the time of entry to be 0 and the time of re-entry to be $t_{r} . \Phi(\cdot)$ is a function which gives the probability of action $\tilde{a}$ resulting in a trade at time $t$ for an order submitted in state $s$ by a trader with private exogenous motive for trade $\nu$. $f(\cdot)$ gives the density function of the fundamental value at time $t$ for an order submitted in state $s . q\left(\nu+v_{t}-\tilde{p}\right)$ is the payoff at the instant of order execution where $\tilde{q}$ is the submitted quantity and $\tilde{p}$ the trade price. The inner integral is over all possible change of the fundamental price whilst the outer integral is over possible execution times between

\footnotetext{
${ }^{3}$ In which case $p$ is irrelevant.
} 
order submission at 0 and re-entry at $t_{r}$. The payoff function for technical traders is:

$$
\pi_{C}\left(s, \tilde{a}, t_{r}\right)=\int_{0}^{t_{r}} \int_{-\infty}^{\infty}\left(e^{-\rho t} \tilde{q}\left(v_{t}-\tilde{p}\right) \Phi(\tilde{a} \mid s, t)\right) f(v \mid s, t) d v d t
$$

The notable difference in the above is that technical traders do not have exogenous motives for trade. Using this we may construct the Bellman equation for both traders. The value of being in state $s$ for trader $B$ is:

$$
J(s)_{Z}=\max _{\tilde{a} \in X(s)} \int_{0}^{\infty}\left\{\pi_{Z}\left(s, \tilde{a}, t_{r}\right)+e^{-\rho t_{r}} \int_{s^{\prime} \in S_{\theta}} J\left(s^{\prime}\right)_{Z} v\left(s^{\prime} \mid s, \tilde{a}, t_{r}\right) d s^{\prime}\right\} d G(w)
$$

where $v\left(s^{\prime} \mid s, \tilde{a}, t_{r}\right)$ is the probability of observing state $s^{\prime}$ on re-entry given the trader takes action $\tilde{a}$ in state $s$ and re-enters at time $t_{r}$. This time is itself drawn from the exogenously specified exponential distribution with probability distribution $G(\cdot)$ The first term of the right hand side corresponds to the payoff from the order execution prior to re-entry whilst the second term represents the traders' continuation payoff.

\subsection{Model Solution}

The model set out above is analytically intractable. In particular the size of the state space resulting from the potentially infinite number of combinations of orders in the book together with the discontinuous nature of this order book information and the stochastic environment make finding analytical statements of optimal strategies infeasible. ${ }^{4} \mathrm{We}$ therefore employ the numerical approach set out by Pakes and McGuire (2001) to solve the model and identify a Markov perfect equilibrium. This method identifies the optimal strategies for a game with a large, potentially infinite, state space by reducing the problem to only considering those states on the recurrent set. In this paper we follow this approach. However, due to the role of trends on trader behavior, historical order book states are potentially relevant for current behavior. Consequently like Goettler et al. (2009) we do not identify a true Markov perfect equilibrium as not all possible payoff relevant information

\footnotetext{
${ }^{4}$ The number of visited states is typically greater than $10^{9}$ in a given optimization.
} 
is included. Rather the strategies are optimal strategies conditional on the information set and the equilibrium is an approximation of the true Markov perfect equilibrium.

The numerical procedures identifies the optimal action in every state the trader encounters in equilibrium. It works be simulating the market for a long period of time. During this time traders submit orders based on the expected payoffs of those actions and then update the payoffs based on the realized outcomes. After a very large number of order submissions the estimated payoffs for each action converge to the realized payoffs and traders may choose the optimal action in each state.

The simulation starts with an empty order book. Traders arrive randomly following the process described above. When a trader arrives they select the order which has the highest expected payoff conditional on the current state. These payoffs are themselves dependent on the actions taken by other traders in other states. It is not possible to directly calculate these values, however, the numerical procedure outlined below refines each traders payoff beliefs until, in equilibrium, traders beliefs about the payoffs of actions match the realized payoffs. Each order submission changes the state of the order book which in turn changes the state for later traders. The optimization identifies the optimal action for each state conditional on the the distribution of actions, entries, valuations and fundamental price changes present within the market.

In a given state a trader selects the action which maximizes their expected payoff. Let $U_{t}(\tilde{a} \mid s)$ be the expected payoff of action $\tilde{a}$ in state $s$ and let the optimal action at time $t$ be $\tilde{a}^{*}$. If this action is a market order, or a limit order which executes prior to the trader re-entering the market, the traders expected payoff for $\tilde{a}^{*}$ in state $s$ is updated as:

$$
U_{t^{\prime}}\left(\tilde{a^{*}} \mid s\right)=\frac{n}{n+1} U_{t}\left(\tilde{A}^{*} \mid s\right)+\frac{1}{n+1} e^{-\rho\left(t^{*}-t\right)} q\left(\nu+v_{t^{*}}-\tilde{p}^{*}\right)
$$

$n$ is a counter which records how many times action $\tilde{a}^{*}$ has been chosen in state $s$ (subscripts are suppressed for ease of notation). $t^{*}$ is the time at which the order executes, for market orders $t=t^{*}$. The expected payoff, $U_{t^{\prime}}\left(\tilde{a}^{*} \mid s\right)$ is therefore updated so that it is equal to the average payoff achieved when action $\tilde{a}^{*}$ is taken in state $s$. If the order is not executed before the trader re-enters at time $t^{\prime}$ the expected payoff is updated 
as follows:

$$
U_{t^{\prime}}\left(\tilde{a^{*}} \mid s\right)=\frac{n}{n+1} U_{t}\left(\tilde{A}^{*} \mid s\right)+\frac{1}{n+1} e^{-\rho\left(t^{\prime}-t\right)} J\left(s^{\prime}, y_{t^{\prime}}\right)
$$

$J\left(s^{\prime} \mid y_{t^{\prime}}\right)$ is the continuation value of the state the trader observes when they re-enter at time $t^{\prime}$. Whilst the order has not executed the trader still has the possibility to profitably execute the order in the future - i.e. it has a continuation value. In this future state the trader will again take the optimal action so the discounted expected payoff from the future optimal action is used to update the original states' expected payoff. In this way the traders future actions and order execution are used to calculate the traders expected payoff from any action now. Over repeated visits to a state this updating process calculates the expected payoff of each action from order executions and continuation values such that the trader may choose the actions which maximizes their expected payoff.

The first time a state is visited the expected payoff is set to $e^{-r t_{x}}\left(V_{Z}-p\right)$ for a buy order and $e^{-r t_{x}}\left(p-V_{Z}\right)$ for a sell order. $t_{x}$ is the expected time to the arrival of an informed trader with a valuation which would allow trade to occur with an order submitted at price $p$. These payoffs are overly optimistic, they assume that the new trader will submit an order that trades with the order at price $p$ rather than submitting a limit orders and weighting. Over-optimism is important for the optimization process, it will lead the trader to first submit orders with high profits but low chance of execution. Over time the trader will learn that these do not execute and move to less profitable more likely to execute orders. If the trader was pessimistic about execution probabilities they would start with the least profitable orders and never discover if more profitable orders could execute. As such optimism means that all actions in each state are examined allowing correct probabilities to be calculated and the optimal action to be chosen in equilibrium.

In addition to finding the expected payoffs of orders, the optimal adjustment to the fundamental price based on the technical rule must also be found. Technical traders condition the adjustment on the current trend $m_{t}$. The price adjustment is updated as follows: 


$$
\delta_{t+1}\left(m_{t+1}\right)=\frac{n}{n+1} \delta_{t}\left(m_{t+1}\right)+\frac{1}{n+1}\left(v_{t}-v_{t-\tau_{C}}\right)
$$

where $\delta_{0}(\cdot)=0$ and $n$ is the number of times the discretised trend $m_{t}$ has been observed (subscripts are suppressed for ease of notation).

In order to speed up convergence the value of $n$ for each action in all states for both the order submission and the technical rule optimization's are reset to 1 every 500 years of simulation time - approximately every ten billion actions. ${ }^{5}$ Resetting $n$ speeds up the convergence of the algorithm by allowing the expected payoffs to change rapidly as the payoffs of other actions are refined and the optimal actions change. Any state which is not visited in five hundred years of simulated time is deleted, this avoids the problem of too many states being stored in computer memory. In particular many states will be visited only at the start of the optimization as order execution probabilities are inaccurate. Once execution probabilities are optimized and these states are no longer visited they no longer form part of the recurrent set and so may be safely ignored.

\subsection{Existence of Equilibria}

In order to verify that the model has converged and the that behavior of traders is optimal the correctness of the expected payoffs are statistically tested using the same approach as Bernales (2014). The optimization method is first run for several billion order submissions. After this point the expected payoffs are held constant (the optimization procedure is not applied) and the model run for a further billion orders. During this period the realized payoffs from orders are recorded. For all states visited during this period the realized payoffs are compared to the expected payoffs. The model is said to be converged if the difference between the two is small: if the mean absolute deviation between payoffs and expected payoffs weighted by the number of times a state is visited is less than 0.02 and the correlation between the realized and expected payoffs is greater than $0.99 .^{6}$ If the model does not match these requirements the optimization procedure and test are

\footnotetext{
${ }^{5}$ We assume 6.5 hours of trading per day and 22 trading days per month.

${ }^{6}$ Different criteria for convergence were tried but it was found that the results were qualitatively similar for values of the mean difference less that approximately 0.03 and the correlation greater than 0.98 .
} 
repeated until convergence is achieved. If it does pass this test it shows the expected payoffs match reality and the equilibrium has been found. Once convergence occurs the model is simulated for a further billion order submissions during which time statistics are calculated.

\subsection{Parametrization}

In order to ensure the model is numerically tractable the state space is simplified by using relative prices. In the model above the absolute price level does not affect a traders strategy, rather payoffs are based on the difference between the execution price and the traders valuation. We therefore define the order book state and each traders possible actions relative to a reference price - the fundamental price observed with the appropriate lag. Note we do not use the current fundamental price as it would implicitly give the traders access to this information. Doing this means that the price level does not matter only the configuration of orders and the traders valuation relative to the current fundamental value.

Traders observe the following information when they enter the market: The prices of the best bid and ask, the quantity at the best bid, the quantity at the best ask, the total quantity of all buy orders, the total quantity of all sell orders, their private valuation and their type. Additionally technical traders observe the current trend. This is rounded to the nearest tick to ensure a finite set of revisited states. ${ }^{7}$ Both the best bid price and the best ask prices are measured in ticks relative to the traders' reference price. If there are no bids and or offers in the book the best bid is set equal to $v_{t-\tau}-n$ and the best ask to $v_{t-\tau}+n$. Traders may place orders at any tick $\pm n$ from their reference price where $n=13$.

The values of the parameters controlling trader entry, trader re-entry and fundamental price changes are based on empirical data. In particular we base them on the trade data

\footnotetext{
${ }^{7}$ We additionally bound the rounded trend to lie between \pm 3 . Due to the stochastic arrival process and valuation distribution, without these bounds the trend may potentially reach arbitrarily high or low values which even after long periods of optimization, had not previously been observed and so not optimized. The results presented below demonstrate that this range is sufficient to provide technical traders with useful information, and is additionally is wider than the average spread.
} 
for large cap stocks in the S\&P500 for the second quarter of 2013. The large cap index was chosen as it consists of stocks which are generally highly liquid and heavily traded. As such they are a natural choice on which to base a simulation of short term trends. Whilst less liquid stocks may also exhibit relatively short term trends in prices the degree of illiquidity will potentially effect the degree to which this occurs. During this period there were approximately 20700 trades per stock per day. In the context of this model each trade involves two traders who leave immediately after the trade occurs. A day in these market lasts 6.5 hours which corresponds to a trader entering, $\lambda_{a}$, on average every 0.56 seconds.

The reentry rate is calculated for data on the life-time of orders for the same stocks over the same period. The distribution of order life times shows that the vast majority of orders have relatively short lifetimes, however, there are a significant number which are submitted and then survive for the whole trading day. Only being canceled at the end of the day. In this model we are focused on active traders who monitor and revise their orders frequently and do not consider these submit and forget orders. We therefore restrict the sample to orders which are in the market for no more than an hour - this accounts for approximately $92 \%$ of the total order cancellations. ${ }^{8}$ Based on this data orders are revised on average every 5.8 seconds, we therefore set $\lambda_{r}=5.8$.

We use the same approach to specifying volatility as Bernales (2014) based on the work of Zhang (2010) who found that the daily volatility of U.S. stock returns was 0.033. We assume an average stock price of $\$ 30$, that each tick corresponds to 0.01 and innovations are of one tick. Under these assumptions $\lambda_{v}=9.55$ seconds. We refer to this as the low volatility regime and contrast this with a high volatility regime where $\lambda_{v}=4$.

Like Goettler et al. (2009) and Bernales (2014) the support of the private value distribution $\nu$ is $\{-8,-4,0,4,8\}$. The probability of private values of -8 and 8 are 0.15 each, for -4 and 4 they are 0.2 each and 0.3 for a value of 0 . This distribution is based on the empirical work of Hollifield et al. (2006) who estimate individual private value distributions for stocks on the Vancouver Stock Exchange. In the discussions below we term those

\footnotetext{
${ }^{8}$ Including all orders in the calculation increases the average order life time by an order of magnitude - which means that orders are rarely revised relative to the arrival of new traders.
} 
traders with a private valuation of 0 as speculators. These individuals may only trade profitably if the asset is mispriced i.e. they may sell the asset above the fundamental value or buy it at a price below. They have no intrinsic motivation to trade.

We set the discount rate $\rho=0.1$ and the parameter controlling the estimation of trends, $\lambda=0.3$. Experiments were conducted with different values of both of these parameter, however, the results were qualitatively similar. The lags with which technical and informed traders observe the fundamental value are varied independently. For both groups we define the set of possible lags as $\tau=\{0,10,20\}$ seconds. We focus on two cases. In the first both groups of traders have the same lag, $\tau_{I}=\tau_{C}$ chosen from the set $\tau$. In the second case informed traders observe the fundamental value without lag i.e. $\tau_{I}=0$ whilst the technical traders lag is varied in the set $\tau .{ }^{9}$

Several studies have estimated the fraction of technical traders within financial markets. The results, however, vary substantially. Allen and Taylor (1990) and Taylor and Allen (1992) found that 90\% of traders on the London FX market used technical analysis to some extent and that this was particularly common for short range forecasts. In contrast Lewellen et al. (1980) found that 27\% of American investors used technical analysis (although amongst those investors with the highest turnover this was 38\%) whilst Hoffmann and Shefrin (2014) found 32\% of Dutch investors employed this technique. Menkhoff and Taylor (2007) conducted a survey of eight surveys and found that in nearly all cases the weight given to technical analysis in decision making was between $30 \%$ and $50 \%$. In this paper we focus on technical traders as speculators. i.e. those traders who do not have an exogenous reason to trade. Instead these traders may use the technical rules in order to out-perform other speculators. We take a parameter value in the range above and set $\gamma=0.5$ i.e. technical traders make up $50 \%$ of the speculators arriving at the market. We contrast these results with the case in which all traders are informed $(\gamma=1.0)$. Note, importantly under this specification the distribution of private valuations remains unchanged and so the results for the two specification may be compared.

\footnotetext{
${ }^{9}$ We do not consider the case $\tau_{C}<\tau_{I}$ i.e. in which technical traders have better information than informed traders in addition to the use of technical rules. In this case technical traders could ignore the information from the momentum estimate and still have an advantage.
} 


\section{Results}

In this section we present results for the model set out above. For each parametrization we run multiple optimizations using different random seeds to ensure that the model converges to the same equilibrium. The results presented below are calculated when the model has reached equilibrium.

\subsection{Profitability of Trading}

There is much debate about the profitability of technical trading strategies and consequently their role in investment. Allen and Karjalainen (1999) and Marshall et al. (2006) argue that these rules are not useful whilst Brock et al. (1992), Neely et al. (1997) and Neely and Weller (2013) demonstrate that they may provide positive returns. In this section we consider the profitability of technical rules in detail. We do this in a setting in which all traders have equal information about the fundamental value, consequently any differences in profits are solely due to the application of the technical rule.

[Table 1 about here.]

Table 1 presents results showing the average profits per order for each group of traders within the market. In analyzing the profitability of the traders we use the definitions given by Hollifield et al. (2006). Profit is defined as the gains from the traders transaction discounted to the point at which they entered the market i.e. $\left(\nu+v_{t}-\tilde{p}\right) e^{\rho t_{p}}$ where $t_{p}$ is the length of time the trader has been in the market. The waiting cost is defined as $\nu\left(e^{\rho t_{p}}-1\right)$ and captures the traders cost in delaying trade. The money transfer is defined as $\left(v_{t}-\tilde{p}\right) e^{\rho t_{p}}$ and captures the gains or losses from the activity of trading itself excluding any gains from the traders private valuation.

The results show that speculators using technical information make higher profits than those who do not. In this the model agrees with the empirical finding of Brock et al. (1992), that the application of a momentum based technical rule makes positive returns. The profits of technical traders are increasing in the lags with which the fundamental value is observed. The amount of additional information provided by the technical rules increases 
as knowledge about the fundamental value becomes less precise. The technical rules allow the traders to better estimate the fundamental - in line with the findings of Brogaard et al. (2014). The addition of traders using technical information also benefits Informed speculators. Whilst technical traders outperform other speculators both groups make greater profits than speculators in a market without technical traders. The additional information incorporated into prices by the technical traders improves accuracy of the market prices which allows all speculators to make higher profits.

Profits are decreasing in the information lag. This effect is particularly strong for speculators and less marked for traders with large private valuations. The larger the information lag the less certainty traders have in the current asset value. For traders with large private valuations this is less of a problem. Whilst in all cases their is a general trend for delay costs to increase with lag these traders may still trade with little danger of making a loss through mis-valuing the fundamental. As such they trade quickly as shown by the lower delay cost of traders with larger valuations. In trading faster these traders, however, incur a higher money transfer. This loss is principally captured by speculators, who with a private valuation of zero, make profits solely from this transfer. Speculators are particularly vulnerable to mis-estimating the fundamental value and so their profits decrease the most due to increased uncertainty at larger information lags. In nearly all cases profits are lower in the high volatility regimes than the low volatility case.

In nearly all cases payoffs are lower when volatility is higher. Increased volatility creates greater risk of adverse selection, and when information is lagged, greater mispricing risk. As a result traders wait longer incurring greater delay costs. These are partially, although not fully, offset by more favorable trading opportunities in the form of reduced money transfer. The only group who make greater profits are speculators with no information lag. For these traders the lack of waiting costs coupled with the more frequent fundamental price movements and consequent mispricing of other trader's orders allows the speculators to make greater profits. These greater profits, however, are eliminated when the fundamental price becomes ambiguous under lagged information. ${ }^{10}$

\footnotetext{
${ }^{10}$ For the remainder of the paper we only present results for the low volatility regime. Higher volatility increase the fluctuations in the fundamental value and therefore, with lagged information, also the
} 


\subsection{Market Quality}

The impact of technical traders on the micro-structure behavior of markets is unknown. From a classical viewpoint any price deviations caused by these individuals should be corrected by the informed traders. There is, however, a significant body of work which suggest that uninformed positive feedback traders may be able to survive by effecting the market price (e.g. De Long, 1990). In a non-micro-structure context these traders have been shown to create trends in prices and to increase volatility. There is, however, no model which examines this question in a micro-structure context.

[Table 2 about here.]

Table 2 presents an analysis of market quality. The results show that the addition of traders using technical information leads to a small reduction in volatility and a reduction in the tracking error (the average distance between the market mid-price and the fundamental value). The ability of these traders to observe trends and incorporate this information into the market price is beneficial to the market as a whole. The benefit is greater at larger information lags. As the lag increases the true value of the fundamental becomes more ambiguous and the market becomes less informationally efficient. Technical traders, however, can use information about recent transaction to improve their estimate, and therefore the market's estimate of the current fundamental value. The use of technical information reduces informational inefficiency.

[Table 3 about here.]

A key aspect of market quality is liquidity - the ability of traders to execute orders with minimal price impact. The role of technical traders in liquidity is unclear. The endogenous interaction of transactions and the valuations of technical traders means that the willingness of traders to supply or take liquidity will depend on both the current market state and the recent trend. This potentially leads to technical traders supplying liquidity at some times and taking it at others.

ambiguity. We find the effect of increasing the volatility is generally similar to that of increasing the information lag and so to avoid repetition only present one set of figures. 
Table 3 shows that the addition of technical traders has an ambiguous effect on liquidity. The spread decreases whilst the quantities available both at the best quotes, and in the book as a whole, decrease. Traders using technical information also decrease the variability of these measures. In addition to reducing market volatility these traders also make the order book more stable. This improvement in market quality over time explains the ambiguous effect on the absolute quantities of orders in the book. The narrower spread and lower volatility encourages traders to trade quickly with market orders as opposed to limit orders. The lower spread reduces the cost of market orders and the lower volatility means that limit orders behind the best quotes are less likely to execute - as such there is less benefit to waiting. This results in there being fewer limit orders in the book, reducing the quantity available. As the information lag increases, the spread, and the quantities at the best bid and in the book as a whole all increase. Traders become more conservative in their order placement due to increased ambiguity in the fundamental value. They use more limit orders and fewer market orders in order to avoid overpaying for the asset.

Whilst liquidity is an indication of the ability of traders to make their desired transactions for low costs it only gives an aggregate picture and does not consider when traders actually want to trade. In order to gain insight into the execution costs of traders we examine the effective spread. The effective spread is defined as: $2 q^{j}\left(p_{x}^{j}-p_{t}^{m}\right)$ where $q^{j}$ is the quantity of the order submitted by a trader of type $j, p_{x}^{j}$ is the execution price and $p_{t}^{m}$ the mid-price at time $t$ when the order was submitted. The effective spread is calculated for informed and technical traders separately. In markets composed only of informed traders with no lag the effective spread is greater than the market spread. This means that on average traders have to pay a high cost to transact. Whilst the spread itself may be relatively narrow there is little liquidity available at this width at the times traders want to trade. As a result traders frequently have to trade at less favorable terms with a wider spread. For liquidity suppliers this is positive as it indicates that profits may be made by submitting limit orders behind the best quotes as they have a significant chance of executing. 
With lagged observations of the fundamental value the effective spread decreases despite the spread itself being greater. At first glance this appears to be counter-intuitive, however, the variability of the spread indicates the mechanism driving this result. The spread in these markets is much more variable than the market without lags - the standard deviation is at least three times greater. This means that whilst the spread on average is larger, traders may wait for periods in which it narrows and so trade at points when costs are relatively small. The variability in the spread itself is driven by the ambiguity in the fundamental value and the greater tracking error. At times when traders are more unsure of the fundamental the spread widens, whilst when their is less ambiguity the spread decreases and trades occur.

The addition of technical traders has a significant impact on the effective spreads at all non-zero lags. The effective spreads of informed traders increases showing an increased cost of trade. The lower quantities available at the best quotes and throughout the book as a whole, coupled with the generally lower spread, mean that when they need to trade informed traders are likely to be in increased competition due to the technical traders. As such there will be less available liquidity and the trading cost will be higher. The effective spreads of technical traders, however, are greater. This is driven by the different distributions of private valuations. Technical traders all act as speculators with private valuations of zero. As such they may only trade when there is a mispricing - when the buy price is above or the sell price below the fundamental value. In contrast other informed traders have non-zero private valuations and so may trade when the asset is not mispriced and the effective spread is much smaller. The effective spread in this case indicates the relative scarcity of trading opportunities for technical traders.

[Figure 1 about here.]

Figure 1 shows graphs of the average order book depth at a range of quotes and the one sided order book depth (the buy side is symmetrical to the sell side). In all cases the graphs are centered on the fundamental value and ticks are given relative to this. Figures are presented for three lags for markets with informed and technical traders. ${ }^{11}$ In all

\footnotetext{
${ }^{11}$ Markets with informed traders only follow a similar pattern.
} 
cases the order book is very concentrated - there are almost no orders placed more than 5 ticks behind the best quotes in the market with $\tau=0$. Increasing values of $\tau$, however, lead to less concentration of orders around the best quotes. In each case the best quotes and the spread are visible in the center. The best bid and ask appear as peaks with the spread between them being the area of lower quantity. On average the best quotes are at the two peaks, however, in times of excess demand or supply these may move with the traders demand for liquidity. The one sided image of the book verifies this. The peak is at the best quote which in all cases is one tick below the fundamental. There is relatively little volume to the left and almost no volume beyond one tick above the fundamental. Whilst liquidity in-balances may occasionally cause traders to place limit orders across the spread these are rare. Increasing information lags, however, changes this pattern. The number of occasions in which traders place limit orders beyond the fundamental increases - the volume of buy orders in the market with $\tau=0$ at one tick over the fundamental is approximately half of the volume in the market with $\tau=20$. Importantly, it should be noted that the traders in this case do not perceive the current fundamental. The net effect is an increase in the aggressiveness of orders relative to the true fundamental. At the same time there is more movement in the location of the spread which may be seen by the smaller peaks at the best quotes and smaller dip at the fundamental value in the combined book, a result of the best quotes moving more frequently.

\subsection{Strategy}

In order to understand how the presence of technical traders leads to the results in the previous section it is necessary to consider the strategies that the traders employ. Previous studies in this area have often been forced to assume arbitrary behavior of technical traders. For instance in Chiarella et al. (2009) traders select a price from a range at random and then choose an order based on the relationship between this price the best quotes and the price at which the agent would be satisfied with their portfolio. The approach taken in this paper, however, has identified the optimal order submission strategy for both groups of traders. In this section we consider these strategies and how they effect 
the market as a whole.

[Table 4 about here.]

The realized behaviors of traders, their order submissions, may be seen in Table 4 . The table shows the number of market orders and limit orders that each type of trader submits. The limit orders are broken into three groups: Those between the best quotes, those at the best quotes and those behind the best quotes (with less favorable prices). Due to the symmetry of the model buy and sell orders are added together. The results show that when only informed traders are present they adopt relatively aggressive strategies: approximately $20 \%$ of orders are market orders whilst a further $17 \%$ are price improving limit orders. Only $6 \%$ of orders are placed behind the best quotes. This indicates that within this market orders behind the best quotes have a low chance of executing. To avoid waiting costs and ensure execution traders adopt aggressive strategies. As information lags increase the fraction of aggressive orders decreases as traders become unsure of the fundamental value. As a result they submit more limit orders behind the best quotes to benefit from other traders desire to trade immediately. The speculators in these markets predominantly submit limit orders at or behind the best quotes. Due to them having a private valuation of 0 , and the spreads being relatively narrow, market orders and price improving limit orders are rarely profitable. Speculators, therefore, attempt to make profits from providing liquidity.

The addition of technical traders has a marked effect on the strategies of informed traders. The fraction of aggressive orders (market and price improving limit orders) both increase predominantly at the expense of limit orders at the best quotes. This change is in reaction to the behavior of the technical traders. Informed traders become less willing to wait when they see a profitable trading opportunity due to the additional information that technical traders gather about the trend. As such they trade quickly to avoid being picked off or losing profitable opportunities.

Given they have the same private values, technical traders place a very similar distribution of orders to speculators. This means they submit a very high proportion of orders at the best quotes. They, along with speculators, also increase the number of orders 
they submit between the best quotes and which improve the price relative to speculator behavior in a market without technical traders. As such, technical traders increase the liquidity provision within the market. This finding relates to the debate regarding maketake fees. These fee structures pay traders for supplying liquidity and charge them for taking it. It has been argued that the strategies of high frequency technical traders are heavily effected by these fees - rather than using market orders they use limit orders to benefit from the liquidity provision fee. Our results, however, show these fees are not necessary for this strategy to be optimal - technical traders may use predominately limit orders even without this fee compensation.

[Table 5 about here.]

Table 5 shows a further relationship between the behavior of traders and the market composition. It can be seen from the table that the addition of technical trader to the market decreases the average amount of time it takes for fundamental traders to execute their orders for all lags. The decreased spreads, together with additional competition from technical traders, makes informed traders more likely to take the gains from trade when they are available rather than waiting. The technical traders in contrast have longer waiting times. As was described above this is evidence that these traders wait for opportunities - keeping limit orders in the book to exploit potentially large price changes and only using market orders when significant mispricings occur. Both groups spend longer in the market as information lags increase reflecting the increased ambiguity of the fundamental value. Traders become more cautious submitting orders further from the fundamental and so reducing the fraction of orders picked off. Technical traders change their orders most frequently when returning to the market whilst informed traders change their orders less often in markets with technical traders. Technical traders use their additional information to identify mispricings more quickly than informed traders and so take available opportunities. As such informed traders may miss opportunities and so choose not to sacrifice priority in the order queue for a potentially too late price improvement.

[Table 6 about here.] 
The behavior of traders changes in response to the market state, in particular the value of the fundamental relative to the best quotes. Table 6 presents the order submission behavior of both groups of traders when the fundamental is above the best ask (results for when it lies below the best bid are similar). As expected technical traders and speculators almost completely stop using sell orders - instead choosing to submit buy orders. The frequency of market orders and price improving limit orders, which attempt to gain better prices without paying the cost of crossing the spread both significantly increase with a corresponding decrease in sell orders. ${ }^{12}$ Informed traders, in contrast, change their behavior to a smaller degree. These traders start to use more market orders - predominantly buy orders but also sell orders. The under-pricing of the asset is taken as an opportunity by most trader to buy it cheaply, however, some traders with relatively high private values take the opportunity of the higher trade volumes to sell the asset at a better price.

[Table 7 about here.]

Biais et al. (1995) documents the occurrence of positive correlation in order flow orders of the same type tend to follow each other. Table 7 shows that this relationship is observed in some specifications of our model. The table present the fraction of times that an order of the row type is followed by an order of the column type. Positive correlation is indicated when the values on the diagonal are above the average for the column. The pattern is present in markets with mixed populations and is most pronounced in those with greater lags. This is intuitive - larger information lags permit greater mispricings and therefore larger trends in their correction. Technical traders will identify these patterns and copy the order submissions of other traders in the market. Further if a technical trader buys the asset following a trend they will reinforce the trend causing later technical traders also to buy. In the case of markets with only informed traders the diagonal rule is only weakly present in markets with a lag. The maximum in most columns is on the reverse diagonal. This shows a tendency for reversion - buy orders following sell orders and

\footnotetext{
${ }^{12}$ When comparing the tables it is important to note that Table 4 adds both buy and sell orders together.
} 
liquidity taking orders following those supplying it. This results from all traders sharing a common view of the fundamental and a symmetric distribution of private valuations around this value. When a trader with a high valuation submits a market buy order they will deplete liquidity on the sell side. This will mean that the next trader who enters with a suitable valuation will be able to profitably supply liquidity. Similarly if a trader supplies liquidity and narrows the spread it is more likely that the next trader will take that liquidity. The presence of technical traders changes this pattern - the additional information they observe depend on the actions of other traders within the market. An order of a given type will in some cases tend to encourage more similar orders rather than reversions. As such the presence of technical traders is important for capturing the order flow in financial markets.

\subsection{Asymmetric Information}

The analysis presented above show the effect of traders using technical information on the micro-structure dynamics and the behavior of traders in the market. Within this analysis it was assumed that technical and informed traders were equally informed about the fundamental value and that technical information was used in addition. Many studies, however, take a different approach assuming that technical measures are used as a substitute for the analysis of the fundamental value of an asset. For example De Long (1990) consider positive feedback traders who trade on trends in the underlying asset rather than deviations from the fundamental value. Similarly papers such as Chiarella et al. (2009) explicitly consider two groups of traders - fundamentalist who know the current fundamental value of the asset and technical traders who do not. In this section we contrast the results presented above with this alternative viewpoint in which traders using technical information are less informed.

[Table 8 about here.]

We model informed traders as knowing the current value of the fundamental value, i.e. $\tau_{I}=0$. Technical traders are less well informed, their lag is varied within the set 
$\{0,10,20\}$. Table 8 presents results showing the effect of this on market liquidity and quality. The presence of technical traders harms market quality. Liquidity is reduced; the spread and effective spread increase whilst the quantity available at the best quotes and throughout the book decrease. At the same time market volatility and the tracking error increase. These negative effects increases with the information lag technical traders are subject to.

From these results it may be seen that technical traders reduce the market efficiency. Even though there are more informed traders than uninformed they are not able to completely remove the negative impact of the technical traders on the market. This constraint differs from the classical limits to arbitrage argument made by Shleifer and Vishny (1997) in which the financial constraints of the arbitrageurs constrain price correction. In this case the limit is driven by the micro-structure - in particular the limit of a traders ability to monitor the market in the presence of a stochastic fundamental value. The possibility of the fundamental value changing between order submission and a trader being able to resubmit their order results in picking off risk and constrains the quantity traders are willing to place in the market. Consequently it is possible for technical traders to deplete liquidity and drive the price away from the fundamental even in the presence of a majority of informed traders.

[Table 9 about here.]

[Table 10 about here.]

The presence of technical traders in the market also effects trading behavior (Table 9). Informed traders become more aggressive, using more market orders and price improving limits orders in order to trade quickly and take advantage of mispricings by technical traders. This can also be seen by the reduced time in the market of informed traders (Table 8). In contrast technical traders become increasingly cautious in comparison to informed speculators as the information lag increases, using larger numbers of limit orders behind the best quotes in an attempt to avoid being picked off. At the same time they observe less favorable trading opportunities and so use fewer market orders. Table 10 
shows that this effects the profits of technical traders. As the lag increases technical traders profits go down. In contrast informed traders profits increase, with the majority of the benefit going to the informed speculators who exploit the technical traders lack of knowledge about the exact fundamental value in order to make increased returns. In conclusion whilst technical information may be beneficial to the traders using it and the market as a whole it is not sufficient to protect these traders from exploitation by better informed individuals at short time periods.

\section{Conclusion}

Despite the presence of large numbers of technical traders operating in financial markets there has been little work looking at the optimal behavior of these individuals in a microstructure context. In this paper we present a model of an order book based financial market containing both technical and informed traders. We use the numerical approach of Pakes and McGuire (2001) and Goettler et al. (2009) to derive optimal strategies for both groups of traders and analyze both the nature of these strategies and the behavior of the market.

We find traders using technical information out-perform those not using information about trends. The presence of technical traders, however, increases the profits for all speculators. This is predominantly done through capturing the spread - both speculators and technical traders submit more limit orders than in the case without technical information. Technical traders, therefore, predominantly act as liquidity suppliers. The presence of technical traders has an ambiguous effect on the market quality. The spread decreases but at the same time the number of orders in the book also falls. Price efficiency increases and the market price tracks the fundamental more accurately. The lag with which the fundamental value is observed by traders has a significant effect. The greater this lag, the more ambiguity there is about the true fundamental value. This allows technical traders to further leverage their informational advantage and make greater profits. The presence of technical traders also results in a closer match between the pattern of correlations seen in the model order flow and those observed in reality. If technical traders are less well 
informed than the other traders then despite access to information about trends they make lower returns than informed traders.

There are several directions in which this model may be expanded in the future. One important area would be to make the determination of trader types endogenous. Momentum based technical strategies aim to exploit trends. When trends are present these traders become more aggressive. In this model the probabilities of trader types were fixed, however, allowing the probability of technical traders to increase or decrease based on price trends could provide further insight into the behavior of these markets. A second area in which the model may be advanced is that traders currently only make a single trade and then leave the model. This misses an important issue: short term traders make profits by rapidly buying and selling the asset, with their profitability being determined by the difference in these prices. The current setting of private valuations partially captures this by requiring a trader to buy below (sell above) a particular price, however, it ignores the consideration of identifying appropriate orders to achieve round trip trades and minimize inventory costs. A related enhancement would be to allow traders to submit orders for multiple units of the asset. In this model traders may only place a single order for one unit, however, many trading strategies involve the use of multiple orders either to control risk or exploit opportunities. 


\section{References}

Allen, F., Karjalainen, R., 1999. Using genetic algorithms to find technical trading rules. Journal of Financial Economics 51 (2), 245-271.

Allen, H., Taylor, M. P., 1990. Charts, noise and fundamentals in the london foreign exchange market. Economic Journal 100 (400), 49-59.

Bernales, A., 2014. Algorithmic and high frequency trading in dynamic limit order markets. Tech. rep., University of Chile.

Biais, B., Hillion, P., Spatt, C., 1995. An empirical analysis of the limit order book and the order flow in the Paris bourse. Journal of Finance 50 (5), 1655-1689.

Brock, W., Lakonishok, J., LeBaron, B., 1992. Simple Technical Trading Rules and the Stochastic Properties of Stock Returns. Journal of Finance 47 (5), 1731-64.

Brogaard, J., Hendershott, T., Riordan, R., 2014. High-frequency trading and price discovery. Review of Financial Studies, Forthcoming.

Chiarella, C., Iori, G., 2002. A simulation analysis of the microstructure of double auction markets. Quantitative Finance 2 (5), 346-353.

Chiarella, C., Iori, G., Perell, J., 2009. The impact of heterogeneous trading rules on the limit order book and order flows. Journal of Economic Dynamics and Control 33 (3), $525-537$.

De Long, J Bradford, e. a., 1990. Positive Feedback Investment Strategies and Destabilizing Rational Speculation. Journal of Finance 45 (2), 379-95.

Goettler, R. L., Parlour, C. A., Rajan, U., 2005. Equilibrium in a dynamic limit order market. The Journal of Finance 60 (5), 2149-2192.

Goettler, R. L., Parlour, C. A., Rajan, U., 2009. Informed traders and limit order markets. Journal of Financial Economics 93 (1), 67-87.

Haldane, A. G., 2010. Patience and finance. Tech. rep., Bank of England. 
Hendershott, T., Jones, C. M., Menkveld, A. J., 2011. Does Algorithmic Trading Improve Liquidity? Journal of Finance, American Finance Association 66 (1), 1-33.

Hoffmann, A. O. I., Shefrin, H., 2014. Technical analysis and individual investors. Journal of Economic Behaviour and Organization, Forthcoming.

Hollifield, B., Miller, R., Sandas, P., Slive, J., 2006. Estimating the gains from trade in limit order markets. Journal of Finance 61 (6), 2753-2804.

Ladley, D., Schenk-Hoppé, K. R., 2009. Do stylised facts of order book markets need strategic behaviour? Journal of Economic Dynamics and Control 33 (4), 817-831.

Lensberg, T., Schenk-Hopp, K. R., Ladley, D., 2012. Costs and benefits of speculation. Discussion Papers 2012/12, Department of Finance and Management Science, Norwegian School of Economics.

Lewellen, W. G., Lease, R. C., Schlarbaum, G. G., 1980. Portfolio design and portfolio performance: The individual investor. Journal of Economics and Business 32 (3), 185197.

Marshall, B. R., Young, M. R., Rose, L. C., 2006. Candlestick technical trading strategies: Can they create value for investors? Journal of Banking \& Finance 30 (8), 2303-2323.

Menkhoff, L., Taylor, M. P., 2007. The Obstinate Passion of Foreign Exchange Professionals: Technical Analysis. Journal of Economic Literature 45 (4), 936-972.

Neely, C., Weller, P., Dittmar, R., 1997. Is Technical Analysis in the Foreign Exchange Market Profitable? A Genetic Programming Approach. Journal of Financial and Quantitative Analysis 32 (04), 405-426.

Neely, C. J., Weller, P. A., 2013. Lessons from the evolution of foreign exchange trading strategies. Journal of Banking \& Finance 37 (10), 3783-3798.

Pakes, A., McGuire, P., 2001. Stochastic algorithms, symmetric markov perfect equilibrium, and the 'curse' of dimensionality. Econometrica 69 (5), 1261-81. 
Parlour, C. A., 1998. Price dynamics in limit order markets. Review of Financial Studies $11(4), 789-816$.

Pellizzari, P., 2011. Optimal trading in a limit order book using linear strategies. Working papers, Department of Economics, University of Venice "Ca' Foscari".

Schulmeister, S., 2009. Profitability of technical stock trading: Has it moved from daily to intraday data? Review of Financial Economics 18 (4), 190-201.

Shleifer, A., Vishny, R. W., 1997. The limits of arbitrage. Journal of Finance 52 (1), $35-55$.

Taylor, M. P., Allen, H., 1992. The use of technical analysis in the foreign exchange market. Journal of International Money and Finance 11 (3), 304-314.

Taylor, N., 2014. The rise and fall of technical trading rule success. Journal of Banking \& Finance 40 (C), 286-302.

Zhang, X. F., 2010. The effect of high-frequency trading on stock volatility and price discovery. Tech. rep., Yale University. 

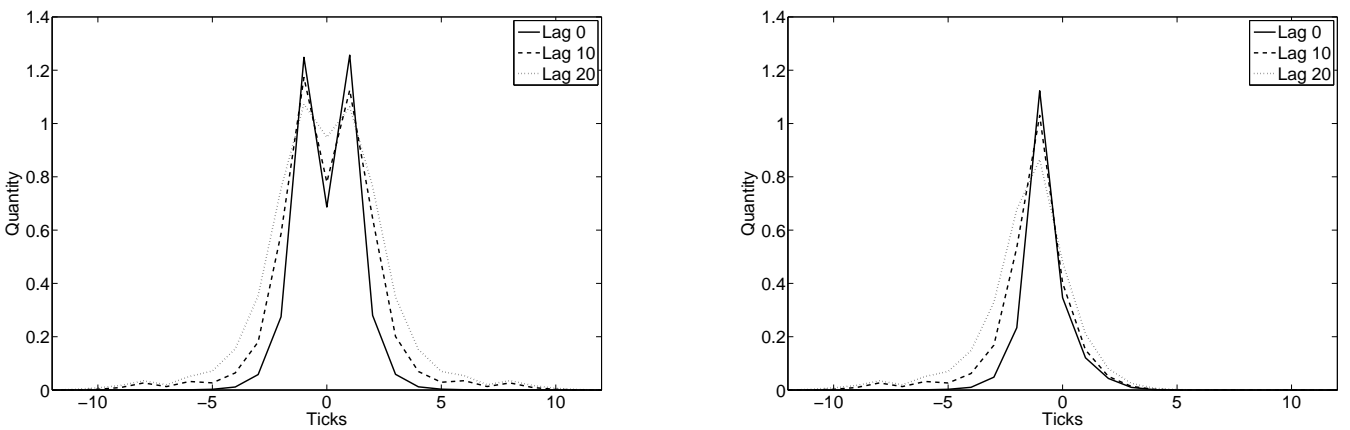

Figure 1: Figure showing the average quantity available in the order book. Left hand panel shows the total volume available in the book - the summation of buy and sell orders at all quotes. The right hand figure shows the average number of buy orders in the order book at all ticks. Sell orders follow a symmetric pattern. Results are calculated from observations at intervals of 10 withing simulation minutes. 


\begin{tabular}{|c|c|c|c|c|c|c|c|}
\hline \multirow{4}{*}{ High Volatility } & \multirow[b]{2}{*}{ Valuation } & \multicolumn{3}{|c|}{$\gamma=0.5$} & \multicolumn{3}{|c|}{$\gamma=1.0$} \\
\hline & & $\tau=0$ & $\tau=10$ & $\tau=20$ & $\tau=0$ & $\tau=10$ & $\tau=20$ \\
\hline & & & & & & & \\
\hline & \multirow{3}{*}{0} & 0.0 & 0.0 & 0.0 & 0.0 & 0.0 & 0.0 \\
\hline Money Transfer & & 0.698 & 0.513 & 0.465 & 0.697 & 0.503 & 0.464 \\
\hline Profit & & 0.698 & 0.513 & 0.465 & 0.697 & 0.503 & 0.464 \\
\hline Delay Cost & \multirow{3}{*}{4} & -0.562 & -0.629 & -0.644 & -0.572 & -0.632 & -0.645 \\
\hline Money Transfer & & -0.139 & -0.145 & -0.146 & -0.134 & -0.149 & -0.151 \\
\hline Profit & & 3.299 & 3.226 & 3.210 & 3.294 & 3.219 & 3.205 \\
\hline Delay Cost & \multirow{3}{*}{8} & -0.414 & -0.443 & -0.462 & -0.409 & -0.448 & -0.466 \\
\hline Money Transfer & & -0.597 & -0.592 & -0.577 & -0.612 & -0.591 & -0.575 \\
\hline Profit & & 6.989 & 6.965 & 6.962 & 6.978 & 6.961 & 6.959 \\
\hline Delay Cost & \multirow{3}{*}{ Technical } & 0.0 & 0.0 & 0.0 & - & - & - \\
\hline Money Transfer & & 0.698 & 0.515 & 0.471 & - & - & - \\
\hline Profit & & 0.698 & 0.515 & 0.471 & - & - & - \\
\hline \multicolumn{8}{|l|}{ Low Volatility } \\
\hline Delay Cost & \multirow{3}{*}{0} & 0.0 & 0.0 & 0.0 & 0.0 & 0.0 & 0.0 \\
\hline Money Transfer & & 0.600 & 0.537 & 0.468 & 0.602 & 0.521 & 0.459 \\
\hline Profit & & 0.600 & 0.537 & 0.468 & 0.602 & 0.521 & 0.459 \\
\hline Delay Cost & \multirow{3}{*}{4} & -0.521 & -0.557 & -0.573 & -0.525 & -0.564 & -0.570 \\
\hline Money Transfer & & -0.168 & -0.175 & -0.176 & -0.166 & -0.175 & -0.175 \\
\hline Profit & & 3.312 & 3.267 & 3.251 & 3.309 & 3.262 & 3.254 \\
\hline Delay Cost & \multirow{3}{*}{8} & -0.307 & -0.359 & -0.343 & -0.298 & -0.334 & -0.339 \\
\hline Money Transfer & & -0.612 & -0.624 & -0.623 & -0.622 & -0.633 & -0.618 \\
\hline Profit & & 7.081 & 7.018 & 7.034 & 7.081 & 7.033 & 7.043 \\
\hline Delay Cost & \multirow{3}{*}{ Technical } & 0.0 & 0.0 & 0.0 & - & - & - \\
\hline Money Transfer & & 0.601 & 0.541 & 0.472 & - & - & - \\
\hline Profit & & 0.601 & 0.541 & 0.472 & - & - & - \\
\hline
\end{tabular}

Table 1: Table showing the profit, waiting cost and money transfer per order. Table showing statistics for traders gains from trade. Profit is defined as $\left(\nu+v_{t}-\tilde{p}\right) e^{\rho t_{p}}$ where $t_{p}$ is the length of time the trader has been in the market. The waiting cost is $\nu\left(e^{\rho t_{p}}-1\right)$ and the money transfer is defined as $\left(v_{t}-\tilde{p}\right) e^{\rho t_{p}}$. Full descriptions are given in the text. Results are calculated for 4 groups of traders based on valuations: Group 0 - those informed traders with $\nu=0$, Group 4 - those traders with $\nu=4$ or $\nu=-4$, Group 8 - those traders with $\nu=8$ or $\nu=-8$, and Technical - who have $\nu=0$. Results computed for market two compositions: $\gamma=1.0$ (Informed traders only), $\gamma=0.5$ (Technical and informed traders) and for two Volatility Regimes: Low Volatility $\left(\lambda_{v}=9.55\right)$ and High Volatility $\left(\lambda_{v}=4\right)$. Results are calculated from approximately $10^{9}$ order submissions. 


\begin{tabular}{|c|c|c|c|}
\hline$\gamma$ & $\tau$ & Volatility & Tracking Error \\
\hline \multirow[t]{2}{*}{0.5} & 0 & 8.19 & 0.80 \\
\hline & & & $(0.87)$ \\
\hline \multirow[t]{2}{*}{0.5} & 10 & 8.26 & 1.06 \\
\hline & & & $(1.13)$ \\
\hline \multirow[t]{2}{*}{0.5} & 20 & 8.25 & 1.28 \\
\hline & & & $(1.23)$ \\
\hline \multirow[t]{2}{*}{1.0} & 0 & 8.19 & 0.80 \\
\hline & & & $(0.88)$ \\
\hline \multirow[t]{2}{*}{1.0} & 10 & 8.28 & 1.10 \\
\hline & & & (1.16) \\
\hline \multirow[t]{2}{*}{1.0} & 20 & 8.30 & 1.38 \\
\hline & & & $(1.30)$ \\
\hline
\end{tabular}

Table 2: Table showing market quality. Volatility is measured in ticks and is based on changes in the mid-price. The Tracking Error is the average absolute distance in ticks between the mid price and the fundamental value. Results computed for market two compositions: $\gamma=1.0$ (Informed traders only), $\gamma=0.5$ (Technical and informed traders). All statistics calculated at intervals of 10 within simulation minutes. Standard deviations where appropriate are shown in parenthesis. 


\begin{tabular}{ccccccc} 
& & & Best Bid & Buy Side & \multicolumn{2}{c}{ Effective Spread } \\
$\gamma$ & $\tau$ & Spread & Quantity & Orders & Informed & Technical \\
\hline 0.5 & 0 & 1.48 & 1.30 & 1.93 & 1.97 & 3.73 \\
& & $(0.62)$ & $(1.13)$ & $(1.63)$ & $(2.22)$ & $(2.22)$ \\
0.5 & \multirow{2}{*}{10} & 2.08 & 1.38 & 2.52 & 1.39 & 2.12 \\
& & $(1.65)$ & $(1.04)$ & $(1.75)$ & $(1.67)$ & $(2.07)$ \\
0.5 & 20 & 2.15 & 1.52 & 3.01 & 1.06 & 1.43 \\
& & $(1.71)$ & $(1.07)$ & $(1.85)$ & $(1.20)$ & $(1.66)$ \\
\hline 1.0 & 0 & 1.51 & 1.33 & 1.95 & 2.02 & \\
& & $(0.64)$ & $(1.15)$ & $(1.61)$ & $(2.22)$ & \\
1.0 & \multirow{2}{*}{10} & 2.22 & 1.47 & 2.63 & 1.28 & \\
& & $(1.91)$ & $(1.09)$ & $(1.70)$ & $(1.52)$ & \\
1.0 & \multirow{2}{*}{20} & 2.39 & 1.57 & 3.09 & 1.04 & \\
& & $(2.10)$ & $(1.11)$ & $(1.80)$ & $(1.11)$ & \\
\hline
\end{tabular}

Table 3: Table showing market liquidity. The best bid quantity is the number of orders at the best bid. The Buy Side Orders are the total number of buy orders in the order book. The spread is the number of ticks between the best bid and best ask. The effective spread is defined as $2 q^{j}\left(p_{x}^{j}-p_{t}^{m}\right)$ where $q^{j}$ is the quantity traded by a trader of type $j, p_{x}^{j}$ is the execution price of trader $j$ 's order and $p_{t}^{m}$ is the mid price at the time trader $j$ submitted their order. The effective spread is calculated and presented for each group of traders. Results computed for market two compositions: $\gamma=1.0$ (Informed traders only), $\gamma=0.5$ (Technical and informed traders). All statistics calculated at intervals of 10 within simulation minutes. Standard deviations where appropriate are shown in parenthesis. 


\begin{tabular}{lllccccccccccc}
\multicolumn{4}{c}{} & \multicolumn{4}{c}{ Market } & \multicolumn{2}{c}{ Limit Order } & \multicolumn{3}{c}{ Market } & \multicolumn{2}{c}{ Limit Order } & \multicolumn{3}{c}{ Technical } \\
$\gamma$ & $\tau$ & Order & Between & At & Behind & Order & Between & At & Behind & Order & Between & At & Behimit Order \\
\hline 0.5 & 0 & 0.241 & 0.198 & 0.504 & 0.057 & 0.032 & 0.104 & 0.770 & 0.094 & 0.031 & 0.106 & 0.767 & 0.096 \\
0.5 & 10 & 0.234 & 0.184 & 0.482 & 0.100 & 0.020 & 0.100 & 0.601 & 0.278 & 0.021 & 0.099 & 0.626 & 0.254 \\
0.5 & 20 & 0.119 & 0.291 & 0.478 & 0.112 & 0.021 & 0.083 & 0.575 & 0.320 & 0.021 & 0.082 & 0.596 & 0.301 \\
\hline 1.0 & 0 & 0.202 & 0.174 & 0.562 & 0.061 & 0.032 & 0.101 & 0.777 & 0.090 & & & \\
1.0 & 10 & 0.191 & 0.158 & 0.531 & 0.120 & 0.021 & 0.093 & 0.653 & 0.233 & & & \\
1.0 & 20 & 0.184 & 0.150 & 0.513 & 0.153 & 0.023 & 0.079 & 0.601 & 0.296 & & & \\
\hline
\end{tabular}

Table 4: Table showing the fraction of orders submitted by each type of trader broken into four categories by their relative position in the book in decreasing order of immediacy from market orders to limit orders between the quotes, at the best quote and behind the best quote. Buy and Sell orders are included together. Results computed for market two compositions: $\gamma=1.0$ (Informed traders only), $\gamma=0.5$ (Technical and informed traders). Results are calculated from approximately $10^{9}$ order submissions. 


\begin{tabular}{|c|c|c|c|c|c|c|}
\hline \multirow{2}{*}{$\gamma$} & \multirow[b]{2}{*}{$\tau$} & \multicolumn{2}{|c|}{ Time to Execution } & \multicolumn{2}{|c|}{ Orders Unchanged } & \multirow{2}{*}{$\begin{array}{c}\text { Picked } \\
\text { Off }\end{array}$} \\
\hline & & Informed & Technical & Informed & Technical & \\
\hline 0.5 & 0 & $\begin{array}{c}1.59 \\
(3.92)\end{array}$ & $\begin{array}{c}5.55 \\
(7.18)\end{array}$ & 0.10 & 0.16 & 0.058 \\
\hline 0.5 & 10 & $\begin{array}{c}2.04 \\
(5.21)\end{array}$ & $\begin{array}{c}7.47 \\
(9.56)\end{array}$ & 0.13 & 0.15 & 0.053 \\
\hline 0.5 & 20 & $\begin{array}{c}2.37 \\
(6.15)\end{array}$ & $\begin{array}{c}9.24 \\
(11.24)\end{array}$ & 0.17 & 0.19 & 0.047 \\
\hline 1.0 & 0 & $\begin{array}{c}2.20 \\
(4.79)\end{array}$ & & 0.12 & & 0.058 \\
\hline 1.0 & 10 & $\begin{array}{c}2.97 \\
(6.58)\end{array}$ & & 0.15 & & 0.054 \\
\hline 1.0 & 20 & $\begin{array}{c}3.50 \\
(7.82)\end{array}$ & & 0.16 & & 0.047 \\
\hline
\end{tabular}

Table 5: Table showing the percentage of orders for each type of trader which are left unchanged when the trader returns to the market and the average length of time between a trader entering the market and their order executing. We define an order as being picked off when $q^{j}\left(v_{t}-v_{s}\right)<0$ where $v_{s}$ is the fundamental at the submission time of the order. This occurs when the trader submits a buy (sell) order and the price decreases (increases) between submission and order execution. Results computed for market two compositions: $\gamma=1.0$ (Informed traders only), $\gamma=0.5$ (Technical and informed traders). Results are calculated from approximately $10^{9}$ order submissions. 


\begin{tabular}{|c|c|c|c|c|c|c|c|c|c|c|}
\hline \multirow{2}{*}{\multicolumn{3}{|c|}{ Trader }} & \multicolumn{4}{|c|}{ Buy Orders } & \multicolumn{4}{|c|}{ Sell Orders } \\
\hline & & & Market & & iit Orc & & Market & & nit Ord & \\
\hline Type & $\gamma$ & $\tau$ & Order & Between & At & Behind & Order & Between & At & Behind \\
\hline Informed & 0.5 & 0 & 0.180 & 0.218 & 0.160 & 0.000 & 0.107 & 0.063 & 0.180 & 0.091 \\
\hline Informed & 0.5 & 10 & 0.168 & 0.189 & 0.143 & 0.032 & 0.110 & 0.058 & 0.197 & 0.104 \\
\hline Informed & 0.5 & 20 & 0.072 & 0.240 & 0.166 & 0.063 & 0.061 & 0.114 & 0.204 & 0.080 \\
\hline Informed & 1.0 & 0 & 0.154 & 0.204 & 0.267 & 0.000 & 0.090 & 0.056 & 0.140 & 0.088 \\
\hline Informed & 1.0 & 10 & 0.140 & 0.170 & 0.229 & 0.050 & 0.087 & 0.049 & 0.160 & 0.115 \\
\hline Informed & 1.0 & 20 & 0.121 & 0.144 & 0.229 & 0.079 & 0.088 & 0.048 & 0.182 & 0.108 \\
\hline Speculator & 0.5 & 0 & 0.054 & 0.172 & 0.628 & 0.002 & 0.000 & 0.000 & 0.000 & 0.145 \\
\hline Speculator & 0.5 & 10 & 0.031 & 0.143 & 0.389 & 0.111 & 0.000 & 0.002 & 0.053 & 0.269 \\
\hline Speculator & 0.5 & 20 & 0.027 & 0.108 & 0.344 & 0.203 & 0.002 & 0.006 & 0.106 & 0.205 \\
\hline Speculator & 1.0 & 0 & 0.052 & 0.156 & 0.657 & 0.001 & 0.000 & 0.000 & 0.000 & 0.134 \\
\hline Speculator & 1.0 & 10 & 0.030 & 0.132 & 0.454 & 0.110 & 0.000 & 0.002 & 0.064 & 0.207 \\
\hline Speculator & 1.0 & 20 & 0.031 & 0.094 & 0.383 & 0.166 & 0.001 & 0.006 & 0.122 & 0.196 \\
\hline Technical & 0.5 & 0 & 0.052 & 0.176 & 0.638 & 0.004 & 0.000 & 0.000 & 0.000 & 0.130 \\
\hline Technical & 0.5 & 10 & 0.034 & 0.140 & 0.434 & 0.127 & 0.000 & 0.002 & 0.059 & 0.203 \\
\hline Technical & 0.5 & 20 & 0.029 & 0.104 & 0.362 & 0.168 & 0.001 & 0.006 & 0.116 & 0.214 \\
\hline
\end{tabular}

Table 6: Table showing the percentage of orders submitted by each type of trader conditional on the fundamental value at the time of submission being greater than or equal to the best ask. Results computed for market two compositions: $\gamma=1.0$ (Informed traders only), $\gamma=0.5$ (Technical and informed traders). Results are broken into eight categories by their quantity and immediacy and are calculated from approximately $10^{9}$ order submissions. Results for the fundamental less than or equal to the best bid follow the same pattern and are available upon request. 
Buy Orders

Sell Orders

\begin{tabular}{|c|c|c|c|c|c|c|c|c|}
\hline & \multirow{2}{*}{$\begin{array}{l}\text { Market } \\
\text { Order }\end{array}$} & \multicolumn{3}{|c|}{ Limit Order } & \multirow{2}{*}{$\begin{array}{c}\text { Market } \\
\text { Order }\end{array}$} & \multicolumn{3}{|c|}{ Limit Order } \\
\hline & & Between & At & Behind & & Between & At & Behind \\
\hline \multicolumn{9}{|l|}{ Mixed $\tau=0$} \\
\hline Buy Market & 0.077 & 0.096 & 0.270 & 0.034 & 0.084 & 0.055 & 0.319 & 0.066 \\
\hline Buy Between & 0.060 & 0.069 & 0.390 & 0.010 & 0.040 & 0.038 & 0.370 & 0.024 \\
\hline Buy At & 0.086 & 0.054 & 0.254 & 0.064 & 0.120 & 0.139 & 0.211 & 0.072 \\
\hline Buy Behind & 0.120 & 0.057 & 0.118 & 0.207 & 0.160 & 0.101 & 0.131 & 0.107 \\
\hline Sell Market & 0.073 & 0.047 & 0.336 & 0.052 & 0.093 & 0.099 & 0.266 & 0.033 \\
\hline Sell Between & 0.036 & 0.035 & 0.430 & 0.018 & 0.058 & 0.062 & 0.353 & 0.009 \\
\hline Sell At & 0.107 & 0.142 & 0.217 & 0.067 & 0.089 & 0.057 & 0.252 & 0.069 \\
\hline $\begin{array}{l}\text { Sell Behind } \\
\text { Mixed } \tau=20\end{array}$ & 0.152 & 0.091 & 0.157 & 0.105 & 0.125 & 0.058 & 0.112 & 0.201 \\
\hline Buy Market & 0.085 & 0.156 & 0.181 & 0.084 & 0.032 & 0.111 & 0.238 & 0.113 \\
\hline Buy Between & 0.040 & 0.062 & 0.398 & 0.014 & 0.024 & 0.061 & 0.390 & 0.011 \\
\hline Buy At & 0.062 & 0.084 & 0.259 & 0.082 & 0.049 & 0.165 & 0.231 & 0.069 \\
\hline Buy Behind & 0.075 & 0.109 & 0.101 & 0.266 & 0.034 & 0.189 & 0.097 & 0.130 \\
\hline Sell Market & 0.032 & 0.105 & 0.243 & 0.112 & 0.083 & 0.160 & 0.187 & 0.078 \\
\hline Sell Between & 0.025 & .063 & 0.380 & 0.030 & 0.043 & 0.058 & 0.391 & 0.010 \\
\hline Sell At & 0.048 & 0.158 & 0.234 & 0.069 & 0.062 & 0.085 & 0.275 & 0.070 \\
\hline Sell Behind & 0.038 & 0.188 & 0.096 & 0.153 & 0.080 & 0.120 & 0.076 & 0.249 \\
\hline Informed & & & & & & & & \\
\hline Buy Market & 0.083 & 0.091 & 0.261 & 0.021 & 0.087 & 0.053 & 0.347 & 0.058 \\
\hline Buy Between & 0.063 & 0.067 & 0.360 & 0.016 & 0.041 & 0.031 & 0.405 & 0.016 \\
\hline Buy At & 0.091 & & 0.256 & & & 0.123 & 0.220 & 0.075 \\
\hline Buy Behind & 0.114 & 0.055 & 0.107 & 0.216 & 0.154 & 0.095 & 0.159 & 0.100 \\
\hline Sell Market & 0.077 & 0.044 & 0.360 & 0.050 & 0.093 & 0.095 & 0.262 & 0.019 \\
\hline Sell Between & 0.043 & 0.042 & 0.406 & 0.026 & 0.057 & 0.057 & 0.355 & 0.014 \\
\hline Sell At & 0.105 & 0.128 & 0.241 & 0.061 & 0.091 & 0.056 & 0.265 & 0.054 \\
\hline Sell Behind & 0.151 & 0.096 & 0.160 & 0.090 & 0.122 & 0.068 & 0.107 & 0.205 \\
\hline Informed $\tau=$ & & & & & & & & \\
\hline Buy Market & 0.081 & 37 & 0.254 & & 0.072 & & 0.317 & 0.068 \\
\hline Buy Between & 0.055 & 0.053 & 0.377 & 0.027 & 0.041 & 0.035 & 0.395 & 0.017 \\
\hline Buy At & 0.082 & 0.066 & 0.263 & 0.076 & 0.105 & 0.116 & 0.226 & 0.066 \\
\hline Buy Behind & 0.112 & 0.059 & 0.122 & 0.276 & 0.095 & 0.124 & 0.126 & 0.087 \\
\hline Sell Market & 0.061 & 0.062 & 0.327 & 0.072 & 0.091 & 0.088 & 0.263 & 0.037 \\
\hline Sell Between & 0.039 & 0.031 & 0.383 & 0.034 & 0.063 & 0.053 & 0.376 & 0.021 \\
\hline Sell At & 0.086 & 0.110 & 0.244 & 0.076 & 0.091 & 0.059 & 0.277 & 0.057 \\
\hline Sell Behind & 0.096 & 0.118 & 0.143 & 0.096 & 0.131 & 0.058 & 0.097 & 0.260 \\
\hline
\end{tabular}

Table 7: Table showing the probability of an order of the column type occurring conditional on the previous order being of the row type. In each case the largest probability in each column is highlighted. Each panel presents the fractions for a different market composition. Results computed for market two compositions: $\gamma=1.0$ (Informed traders only), $\gamma=0.5$ (Technical and informed traders). Results are calculated from approximately $10^{9}$ order submissions for each panel. 


\begin{tabular}{ccccccccccc} 
& & & Best Bid & Buy Side & \multicolumn{2}{c}{ Effective Spread } & \multicolumn{2}{c}{ Tracking } & \multicolumn{2}{c}{ Time to Execution } \\
$\tau_{I}$ & $\tau_{C}$ & Spread & Quantity & Orders & Informed & Technical & Volatility & Error & Informed & Technical \\
\hline 0 & 0 & 1.48 & 1.30 & 1.93 & 1.97 & 3.73 & 8.19 & 0.80 & 1.59 & 5.55 \\
& & $(0.62)$ & $(1.13)$ & $(1.63)$ & $(2.22)$ & $(2.22)$ & & $(0.87)$ & $(3.92)$ & $(7.18)$ \\
0 & \multirow{2}{*}{10} & 2.35 & 1.28 & 2.17 & 1.66 & 2.49 & 8.38 & 1.18 & 1.47 & 8.01 \\
& & $(2.09)$ & $(0.98)$ & $(1.57)$ & $(1.87)$ & $(2.04)$ & & $(1.29)$ & $(3.56)$ & $(10.16)$ \\
0 & 20 & 2.77 & 1.25 & 2.30 & 1.49 & 1.69 & 8.43 & 1.43 & 1.46 & 9.08 \\
& & $(2.39)$ & $(0.82)$ & $(1.50)$ & $(1.63)$ & $(1.49)$ & & $(1.37)$ & $(3.46)$ & $(11.93)$ \\
\hline 0 & 0 & 1.48 & 1.30 & 1.93 & 1.97 & 3.73 & 8.19 & 0.80 & 1.59 & 5.55 \\
& & $(0.62)$ & $(1.13)$ & $(1.63)$ & $(2.22)$ & $(2.22)$ & & $(0.87)$ & $(3.92)$ & $(7.18)$ \\
10 & \multirow{2}{*}{10} & 2.08 & 1.38 & 2.52 & 1.39 & 2.12 & 8.26 & 1.06 & 2.04 & 7.47 \\
& & $(1.65)$ & $(1.04)$ & $(1.75)$ & $(1.67)$ & $(2.07)$ & & $(1.13)$ & $(5.21)$ & $(9.56)$ \\
20 & 20 & 2.15 & 1.52 & 3.01 & 1.06 & 1.43 & 8.25 & 1.28 & 2.37 & 9.24 \\
& & $(1.71)$ & $(1.07)$ & $(1.85)$ & $(1.20)$ & $(1.66)$ & & $(1.23)$ & $(6.15)$ & $(11.24)$ \\
\hline
\end{tabular}

Table 8: Table showing market liquidity. The best bid quantity is the number of orders at the best bid. The Buy Side Orders are the total number of buy orders in the order book. The spread is the number of ticks between the best bid and best ask. The effective spread is defined as $2 q^{j}\left(p_{x}^{j}-p_{t}^{m}\right)$ where $q^{j}$ is the quantity traded by a trader of type $j, p_{x}^{j}$ is the execution price of trader $j$ 's order and $p_{t}^{m}$ is the mid price at the time trader $j$ submitted their order. The effective spread is calculated and presented for each group of traders. The tracking error is the average distance in ticks between the mid price and fundamental price. Results computed for markets composed of technical and informed traders $(\gamma=0.5)$. All statistics calculated at intervals of 10 within simulation minutes. Standard deviations where appropriate are shown in parenthesis. 


\begin{tabular}{lcccccccccccc} 
& \multicolumn{4}{c}{ Informed } & \multicolumn{4}{c}{ Speculator } & \multicolumn{4}{c}{ Technical } \\
& Market & \multicolumn{2}{c}{ Limit Order } & Market & \multicolumn{2}{c}{ Limit Order } & Market & \multicolumn{2}{c}{ Limit Order } \\
$\tau_{C}$ & Order & Between & At & Behind & Order & Between & At & Behind & Order & Between & At & Behind \\
\hline 0 & 0.241 & 0.198 & 0.504 & 0.057 & 0.032 & 0.104 & 0.770 & 0.094 & 0.031 & 0.106 & 0.767 & 0.096 \\
10 & 0.234 & 0.184 & 0.482 & 0.100 & 0.020 & 0.100 & 0.601 & 0.278 & 0.021 & 0.099 & 0.626 & 0.254 \\
20 & 0.119 & 0.291 & 0.478 & 0.112 & 0.021 & 0.083 & 0.575 & 0.320 & 0.021 & 0.082 & 0.596 & 0.301 \\
\hline
\end{tabular}

Table 9: Table showing the fraction of orders submitted by each type of trader broken into four categories by their relative position in the book in decreasing order of immediacy from market orders to limit orders between the quotes, at the best quote and behind the best quote. Buy and Sell orders are included together. Results computed for markets composed of technical and informed traders $(\gamma=0.5)$. Results are calculated from approximately $10^{9}$ order submissions. 


\begin{tabular}{lcccc} 
& \multicolumn{4}{c}{ Trader Type } \\
$\tau_{C}$ & 0 & 4 & 8 & Technical \\
\hline 0 & 0.600 & 3.312 & 7.081 & 0.601 \\
10 & 0.670 & 3.312 & 7.055 & 0.472 \\
20 & 0.787 & 3.313 & 7.009 & 0.364 \\
\hline
\end{tabular}

Table 10: Table showing the profit per order as defined by the difference between the trade price and the traders valuation discounted back to the time of entry for both types of traders in all three market settings. Results computed for markets composed of technical and informed traders $(\gamma=0.5)$. Results are calculated from approximately $10^{9}$ order submissions. 